2 HM Government. Report of the Royal Commission on the Law Relating to Mental IIIness and Mental Deficiency 1954-1957 (Cmnd 169). HMSO, 1957.

3 Guthrie E, McMeekin A, Thomasson R, Khan S, Makin S, Shaw B, et al. Opening the 'black box': liaison psychiatry services and what they actually do. BJPsych Bull 2016; 40: 175-80.

doi: $10.1192 / \mathrm{pb} .40 .6 .348$

\section{Psychiatrists' use of psychological formulation}

In a qualitative study ${ }^{1}$ Mohtashemi et al have helpfully explored the use of psychological formulation by adult psychiatrists. They describe how this is limited in extent and discuss the implications of these findings from the perspective of clinical psychologists. We would like to offer some additional observations from a different perspective, that of psychiatrists with a particular interest in the use of formulation in everyday psychiatric practice.

It is perhaps worth mentioning that the term 'formulation' continues to be used in different ways, as it has been for at least 30 years. ${ }^{2,3}$ Sometimes it denotes a summing up of a case and its management, sometimes an interpretation of why a problem is occurring.

We suggest that many psychiatrists do not share the view that the core tasks of psychiatry should be diagnosis and medication. This is not the position of the Royal College of Psychiatrists, ${ }^{4}$ and in our personal experience colleagues are frequently seeking to practise in a way which is genuinely biopsychosocial. Unfortunately, it is common for psychiatrists to report that pressures of time and the expectations of services and patients lead to diagnosis and medication dominating more than they would wish. When many psychiatrists are trying to practise holistically, we believe that the term 'medical model' as used in the paper is misleading and that the term 'biological model' perhaps more aptly describes the views which Mohtashemi et al see as conflicting with clinical psychologists' perspectives. There is a similar issue in the paper's use of the term 'psychiatric formulation', which seems again to imply something that would not include psychological elements. We strongly believe that, when well conducted, formulation by psychiatrists should always consider psychological elements and that in practice conflict between psychiatrists' and psychologists' views may be less frequent than the paper appears to imply.

While we agree with the authors that team formulation with clinical psychologists is valuable, we think that overemphasising its importance risks overlooking other ways in which formulation may be helpful. Recently, for example, increasing attention has been given to the potential of a dialogical approach, as in the open dialogue model. For clinicians seeing patients who may not go on to be supported by a multidisciplinary team, a relevant skill will be that of conducting initial assessments in such a way that consultation includes thinking collaboratively with the patient about what may be contributing to their problems and, in doing so, giving due respect to psychological and social as well as biological factors, and to the patient's perspective.

We agree that team formulation with clinical psychologists may be helpful in supporting psychiatrists to make more use of psychological formulation and we welcome the suggestion for some overlap in the training of psychologists and psychiatrists. However, we think that if psychiatrists are to make optimal use of psychological formulation, we need to do more than increase contact with clinical psychologists. Most importantly, progress is likely to be limited without attention to the systemic barriers that make it hard even for the most highly motivated psychiatrists to give adequate emphasis to psychological formulation. We believe that training should address psychiatrists' particular needs such as being able to combine understanding of both psychosocial and biological elements - and should recognise the drawbacks of an excessive focus on biological explanations. Having a genuine belief in the value of psychological formulation is likely in itself to have a significant impact on how much it is used. We think that there is scope for making better use of existing training opportunities - such as the Balint groups available in all trusts that train psychiatrists - and for making better use of the requirements for higher specialist training to include ongoing training in psychotherapeutic skills. We believe that greater emphasis on formulation skills in workplace-based assessments and examinations might make a significant difference. Beyond training, consultant Balint groups and other arrangements that support reflective practice are likely to also support development of formulation skills. Medical psychotherapists and other psychiatrists with specialist training in working psychologically are likely to be well placed to contribute to training and support for colleagues, as well as to team formulation.

The study by Mohtashemi et al seems part of a surge of interest in formulation and how it might be used more effectively. The interest has been shared by psychiatrists; the Royal College of Psychiatrists' Medical Psychotherapy Faculty and General Psychiatry Faculty executives have recently agreed good practice guidelines for the use of formulation in general psychiatric practice, and these are likely to be adopted shortly as formal College guidance (details available from the authors on request). An information leaflet for patients based on the same guidance is also being developed. An initiative aiming to enhance training in formulation across disciplines has recently been set up by Health Education England, and the multi-agency working group includes representatives of both the British Psychological Society and the Royal College of Psychiatrists.

\section{Declaration of interest}

A.S., on behalf of the Medical Psychotherapy Faculty Executive Committee, was the lead author of Using Formulation in General Psychiatric Care: Good Practice (Occasional Paper OP103, Royal College of Psychiatrists, 2017).

Alison Summers, Locum Consultant Psychiatrist, Lancashire Care NHS Foundation Trust, UK; email: alison.summers77@gmail.com, and Susan Mizen, Consultant in Medical Psychotherapy, Devon Partnership NHS Trust and Chair, Royal College of Psychiatrists Medical Psychotherapy Faculty Executive Committee

1 Mohtashemi, R, Stevens J, Jackson PG, Weatherhead S. Psychiatrists' understanding and use of psychological formulation: a qualitative exploration. BJPsych Bull 2016; 40: 212-6.

2 Hollyman JA, Hemsi L. What do psychiatrists understand by formulation? A survey of clinicians in a group of hospitals in London. Psychiatr Bull 1983; 7: 140-3.

3 Hollyman JA, Hemsi L. What do the examiners understand by formulation? A survey of the members of the College's board of examiners. Psychiatr Bull 1983; 7: 165-6.

4 Royal College of Psychiatrists (2014). When Patients Should Be Seen by a Psychiatrist (CR184). Available at http://www.rcpsych.ac.uk/ usefulresources/publications/collegereports/cr/cr184.aspx

doi: $10.1192 / \mathrm{pb} .40 .6 .349$

\title{
Bulletin
}

